\title{
Evaluation of feto-maternal outcome using AFI and SDVP for amniotic fluid assessment; Which is a better method?
}

\author{
Biplab Mukhopadhyay ${ }^{1}$, Syed Nawaz Ahmad ${ }^{2 *}$, Shefali Agarwal $^{3}$, Shashi Kabra ${ }^{4}$
}

\author{
${ }^{1}$ Department of Obstetrics and Gynecology, ILS Hospital, Kolkata, West Bengal, India \\ ${ }^{2}$ Department of Obstetrics and Gynaecology, ESI PGIMSR, New Delhi, India \\ ${ }^{3}$ Department of Obstetrics and Gynaecology, AIIMS, New Delhi, India \\ ${ }^{4}$ Department of Obstetrics and Gynaecology, Deen Dayal Upadhyay Hospital, New Delhi, India
}

Received: 11 May 2017

Accepted: 10 June 2017

\section{*Correspondence:}

Dr. Syed Nawaz Ahmad,

E-mail: dr.syednawaz@gmail.com

Copyright: (C) the author(s), publisher and licensee Medip Academy. This is an open-access article distributed under the terms of the Creative Commons Attribution Non-Commercial License, which permits unrestricted non-commercial use, distribution, and reproduction in any medium, provided the original work is properly cited.

\begin{abstract}
Background: Abnormal amniotic fluid volume (AFV) may be the only or earliest sonographic sign of an obstetrical problem. There is no clear consensus on the best method to assess amniotic fluid adequacy. The AFI and the SDVP are the more commonly employed techniques for assessing adequacy of amniotic fluid. This study aimed to compare the maternal and foetal outcome when amniotic fluid was measured by these two methods.

Methods: Hundred pregnant women at $>28$ weeks gestation scheduled for test of biophysical score due to various risk factors were enrolled and divided in two groups of 50 each. In each group, amniotic fluid volume was determined by either calculating the Amniotic Fluid Index (AFI) or measuring the Single Deepest Vertical Pocket (SDVP). Oligohydramnios was declared at cut off of $<5$ for the former and $<2 \mathrm{~cm}$ for the later method respectively. Maternal and foetal outcomes were compared between the two groups.

Results: Diagnosis of oligohydramnios was $45 / 50$ in group I and $23 / 50$ in group II ( $<<0.0001$ ). Induction of labour was done in $70.0 \%$ in group I and $18 \%$ in group II ( $p<0.0001)$. Non-reassuring foetal heart rate was seen in $36.0 \%$ in group I and $14.0 \%$ in group II ( $\mathrm{p}=0.011)$. Rate of caesarean delivery was significantly higher in group I, $42.0 \%$ in comparison of $20.0 \%$ in group II ( $\mathrm{p}=0.017$ ). NICU admission were $32.0 \%$ in group I and $18.0 \%$ in group II ( $\mathrm{p}=0.106)$. Conclusions: SDVP is a better choice for determining amniotic fluid to avoid unnecessary interventions without any significant improvement in peripartum outcome measures.
\end{abstract}

Keywords: Amniotic fluid, Amniotic fluid index, Single deep vertical pocket

\section{INTRODUCTION}

Amniotic fluid provides a supportive environment for foetal development. It protects the foetus from trauma and infection through its dampening and bacteriostatic properties and fosters the development of the foetal musculoskeletal system. Amniotic fluid is maintained in a dynamic equilibrium; its volume is the sum of fluid from foetal urine and lung fluid flowing into and out of amniotic space due to foetal swallowing and intramembranous absorption. ${ }^{1}$ Normally amniotic fluid volume increases to about 1 to $1.2 \mathrm{~L}$ by 38 weeks of pregnancy and starts decreasing thereafter to only 200$300 \mathrm{~mL}$ by 43 weeks. Arbitrarily, more than $2 \mathrm{~L}$ of amniotic fluid at the time of delivery is considered excessive and is termed as polyhydramnios. ${ }^{2}$ Amniotic Fluid Volume (AFV) is an important parameter in the assessment of foetal wellbeing. Oligohydramnios, a decrease in AFV, can occur as a result of multiple maternal, foetal or placental anomalies including intrauterine growth restriction, pre-eclampisa, uteroplacental insufficiency and prolonged (post-term) 
pregnancy. An abnormal AFV may be the earliest or only sonographic sign of an obstetrical problem. ${ }^{3}$ Consequently, it is associated with increased foetal and neonatal morbidity and mortality. Many caregivers practice planned delivery by induction of labour or caesarean section after diagnosis of decreased amniotic fluid volume at term or earlier. ${ }^{4}$ Therefore, the antenatal diagnosis of oligohydramnios is important in the management of pregnancy.

Ultrasonographic methods of assessment of amniotic fluid can be viewed as semi-quantitative. They perform best when identifying normal volumes but are poor when identifying an abnormal volume. In addition to differences in the methods for amniotic fluid assessment, various other factors play a confounding role in the accurate assessment of amniotic fluid by ultrasonography, which include experience of the operator, foetal position at the time of scan, the probability of a transient change in AFV and the different ultrasound diagnostic criteria of an abnormal AFV.

There is no clear consensus on the best method to assess amniotic fluid adequacy. Invasive methods such as indicator dilution techniques are the most accurate measures of AFV, but are impractical for clinical use. The Amniotic Fluid Index (AFI) and the Single Deepest Vertical Pocket (SDVP) are the more commonly employed techniques for assessing adequacy of amniotic fluid. In order to calculate AFI, the operator divides the uterine cavity into four quadrants. In each quadrant, the largest vertical diameter of a fluid pocket (not containing small foetal parts or loops of umbilical cord) is measured. The sum of these four measures provides a single value for the AFI. For calculating the SDVP, the vertical and transverse diameters of the largest pocket of amniotic fluid are measured and recorded, the depth of the pocket measured at a right angle to the uterine contour. On sonography, AFI $>20 \mathrm{~cm}$ or SDVP $>8 \mathrm{~cm}$ is taken as polyhydramnios. For identifying oligohydramnios, different arbitrary cutoff values have been estimated, ranging from AFI being less than $5 \mathrm{~cm}$ to $8 \mathrm{~cm}$ or SDVP $<2 .^{5-10}$

This study intended to compare these two methods for the assessment of amniotic fluid volume as per the outcome of the mother and foetus in pregnancies with oligohydramnios.

\section{METHODS}

This was a prospective cohort study, conducted at a tertiary care hospital in Delhi, India from 2014 to 2016 . A total of 100 patients coming to the hospital for antenatal care who were scheduled for biophysical scoring due to different risk factors were enrolled in this study. The study had the approval of the hospital's ethics committee. All the selected patients were explained about the project and written informed consent was taken from them. Women with singleton pregnancy at >28 weeks of gestation with a live foetus, who needed assessment of foetal wellbeing were enrolled. Women with multiple pregnancy, Rh negative pregnancy and those with congenital malformations in the foetus were excluded from the study.

These women were divided into two equal groups of 50 each, arbitrarily. In the first group assessment of amniotic fluid volume was done by calculating Amniotic Fluid Index and in the second by Single Deepest Vertical Pocket on ultrasonogram. The cut off values were $<5$ and $<2 \mathrm{~cm}$ respectively. The two groups were then compared on the basis of rate of diagnosis of oligohydramnios and maternal and perinatal outcomes. Statistical analysis was performed by Chi-square test. Statistical significance was defined as probability value $<0.05$.

\section{RESULTS}

Age of the patients ranged from 18 to 36 years in both groups with the average age being 22.79 years. The average age of patients in the group I was $23.10 \pm .315$ years and $22.48 \pm 3.506$ years in group II. The gestational age ranged from 28 to 43 weeks in two groups with average of 37.70 weeks. In group I, average gestational age was $37.56 \pm 3.15$ weeks and in group II it was $37.84 \pm 2.881$ weeks.

Table1: Frequency distribution table showing the relative presence of different risk factors in the study population.

\begin{tabular}{|lll|}
\hline Risk factors & $\begin{array}{l}\text { Group I } \\
(\mathrm{n}=50)\end{array}$ & $\begin{array}{l}\text { Group II } \\
(\mathrm{n}=50)\end{array}$ \\
\hline Severe PIH & 0 & $1(2.0 \%)$ \\
\hline Abruption & $1(2.0 \%)$ & 0 \\
\hline Placenta praevia & 0 & $1(2.0 \%)$ \\
\hline Chronic Hypertension & 0 & $1(2.0 \%)$ \\
\hline $\begin{array}{l}\text { Intra-uterine growth } \\
\text { restriction }\end{array}$ & $4(8.0 \%)$ & $6(12.0 \%)$ \\
\hline $\begin{array}{l}\text { Congenital } \\
\text { malformations }\end{array}$ & $3(6.0 \%)$ & $2(4.0 \%)$ \\
\hline PIH & $10(20.0 \%)$ & $11(22.0 \%)$ \\
\hline PIH+APH & $1(2.0 \%)$ & 0 \\
\hline Post-datism & $2(4.0 \%)$ & 0 \\
\hline $\begin{array}{l}\text { Post-term pregnancy } \\
\text { Preterm premature } \\
\text { rupture of membranes }\end{array}$ & $2(4.0 \%)$ & $7(14.0 \%)$ \\
\hline Previous 1 caesarean & $5(2.0 \%)$ & $3(6.0 \%)$ \\
\hline Previous 2 caesarean & $1(2.0 \%)$ & 0 \\
\hline $\begin{array}{l}\text { Premature rupture of } \\
\text { membranes. }\end{array}$ & $3(6.0 \%)$ & $1(2.0 \%)$ \\
\hline $\begin{array}{l}\text { Decreased foetal } \\
\text { movements }\end{array}$ & $4(8.0 \%)$ & $5(10.0 \%)$ \\
\hline Severe anaemia & $1(2.0 \%)$ & $2(4.0 \%)$ \\
\hline
\end{tabular}

Number of patients diagnosed with oligohydramnios was $45(90.0 \%)$ in group I and 23(46.0\%) in group II. Diagnosis of oligohydramnios was significantly more in group I than in group II $(\mathrm{p}<0.0001)$. Labour was induced in $70.0 \%$ patients in group I as compared to $18 \%$ in group 
II, which was statistically significant $(\mathrm{p}<0.0001)$. Nonreassuring foetal heart rate was seen in 18 patients $(36.0 \%)$ in group I and 7 patients $(14.0 \%)$ in group II. This difference was found to be statistically significant $(\mathrm{p}=0.011)$. Incidence of presence of meconium was $44.0 \%$ in group I and $28.0 \%$ in group II $(\mathrm{p}=0.096))$. Rate of cesarean delivery was $42.0 \%$ in group I in comparison to $20.0 \%$ in group II. This difference was statistically significant $(\mathrm{p}=0.017)$. Sixteen neonates $(32 \%)$ from group I and 9 (18.0\%) from group II were admitted to NICU. The difference was not statistically significant $(\mathrm{p}=0.10)$. Perinatal deaths were $4.0 \%(2 / 50)$ in group I and $2.0 \%$ $(1 / 50)$ in group II $(p=0.558)$. High risk factors present in the study population are shown in Table 1 .

\section{DISCUSSION}

Various antepartum foetal surveillance tests have the aim of providing the obstetrician with a tool that guides intervention with the ultimate goal of preventing clear-cut adverse pregnancy outcomes. Both the biophysical profile and the modified BPP include the assessment of AFV as an integral part of testing because decreased AFV (oligohydramnios) is believed to indicate a foetal response to chronic stress. ${ }^{2,11}$ The most common techniques used to assess whether the amniotic fluid is adequate are the AFI and the SDVP measurement. ${ }^{12,13}$ According to these two methods, an AFI of $5 \mathrm{~cm}$ or less or the absence of a pocket measuring $2 \times 1 \mathrm{~cm}$ is indicative of decreased AFV.

In our study, $90.0 \%$ patients were diagnosed to have oligohydramnios when measurement was done using AFI as opposed to $46.0 \%$ in group II, in which measurement was done by the single deepest vertical pocket method, similar to findings in other studies. ${ }^{14-16}$ Understandably, significantly more patients underwent induction of labour in group I and there was an expected increase in number of caesarean deliveries in group I than in group II as elective induction of labour is known to be associated with increased incidence of caesarean section. ${ }^{17}$

However, there was not any statistically significant difference in APGAR score, NICU admissions, perinatal deaths and incidence of meconium stained liquor between the two groups. This implies that the AFI identifies a significantly greater number of women as having oligohydramnios versus the SDVP without much difference in perinatal morbidity and mortality. Normal ultrasonographic values for either AFI or SDVP, implying a normal amniotic fluid volume, are associated with a very low risk of labour complications.

It seems logical to recommend that only one method should be used for foetal assessment tests. According to the ACOG practice bulletin of 2014 also, the SDVP measurement, as opposed to AFI to diagnose oligohydramnios, decreases the rate of unnecessary interventions without increase in adverse perinatal outcomes. $^{18}$

\section{CONCLUSION}

Our study draws the conclusion that the SDVP measurement appears to be the more appropriate method for assessing AFV during foetal surveillance as the use of the AFI increases the rate of diagnosis of oligohydramnios and consequently the rate of intervention in pregnancy without any significant improvement in peripartum morbidity.

\section{Funding: No funding sources}

Conflict of interest: None declared

Ethical approval: The study was approved by the Institutional Ethics Committee

\section{REFERENCES}

1. Ross MG, Brace RA. National Institute of Child Health and Development Conference summary: amniotic fluid biology-basic and clinical aspects. J Matern Foetal Med. 2001;10(1):2-19.

2. Cunningham FG, Williams JW, Leveno KJ, Bloom S, Hauth JC. Disorder of amniotic fluid volume. Williams Obstetrics. 23 ${ }^{\text {rd }}$ ed. New York: Mc GrawHill Medical; 2009:490-99.

3. Hashimoto BE, Kramer DJ, Brennan L. Amniotic fluid volume: fluid dynamics and measurement technique. Semin Ultrasound CT MR. 1993;14 (1):40-55.

4. Sherer DM. A review of amniotic fluid dynamics and the enigma of isolated oligohydramnios. Am J Perinatol. 2002;19(5):253-66.

5. Croom CS, Banias BB, Ramos-Santos E, Devoe LD, Bezhadian A, Hiett AK. Do semiquantitative amniotic fluid indexes reflect actual volume?. Am J Obstet Gynecol. 1992;167(4):995-9.

6. Magann EF, Chauhan SP, Kinsella MJ, McNamara MF, Whitworth NS, Morrison JC. Antenatal testing among 1001 patients at high risk: the role of ultrasonographic estimate of amniotic fluid volume. Am J Obstet Gynecol. 1999;180(6):1330-6.

7. Magann EF, Chauhan SP, Bofill JA, Martin JN. Comparability of the amniotic fluid index and single deepest pocket measurements in clinical practice. Aust N Z J Obstet Gynaecol. 2003;43(1):75-7.

8. Garmel SH, Chelmow D, Sha SJ, Roan JT, D'Alton ME. Oligohydramnios and the appropriately grown fetus. Am J Perinatol. 1997;14(6):359-63.

9. Kawasaki N, Nishimura H, Yoshimura T, Okamura H. A diminished intrapartum amniotic fluid index is a predictive marker of possible adverse neonatal outcome when associated with prolonged labour. Gynecol Obstet Invest. 2002;53(1):1-5.

10. Rogers MS, Wang CC. A comparison of three ultrasound estimates of intrapartum oligohydramnios for prediction of foetal hypoxia-reperfusion injury. Early Hum Dev. 1999;56(2-3):117-26.

11. Gramellini D, Fieni S. Verrotti C, Piantelli G, Cavallotti D, Vadora E. Ultrasound evaluation of' amniotic fluid volume: methods and clinical 
accuracy. Acta Bio-Medica de L'Ateneo Parmense. 2004;75(1):40-4.

12. Phelan TP 1987 Phelan .TP, Smith CY, Broussard P, Small M. Amniotic fluid volume assessment with the four-quadrant technique at 36-42 weeks gestation. J Repro Med. 1987;32(7):540-2.

13. Chamberlain PF, Manning FA, Morrison I, Harman CR, Lange IR. Ultrasound evaluation or amniotic fluid volume. The relationship of marginal and decreased amniotic fluid volumes to perinatal outcome. Am J Obstet Gynecol. 1984;150(3):245-9.

14. Nabhan AF, Abdelmoula YA. Amniotic fluid index versus single deepest vertical pocket: a meta-analysis of randomized controlled trials. Int $\mathbf{J}$ Gynaecol Obstet. 2009;104(3):184-8

15. Magann EF, Chauhan SP, Doherty DA, Magann MI, Morrison JC. The evidence for abandoning the amniotic fluid index in favor of the single deepest pocket. Am J Perinatol. 2007;24(9):549-55.
16. Rosati P, Guariglia L, Cavaliere AF, Ciliberti P, Buongiorno S, Ciardulli A, et al. A comparison between amniotic fluid index and the single deepest vertical pocket technique in predicting adverse outcome in prolonged pregnancy. J Prenat Med. 2015;9(1-2):12-5.

17. Stock SJ, Ferguson E, Duffy A, Ford I, Chalmers J, Norman JE. Outcomes of elective induction of labour compared with expectant management: population based study. BMJ. 2012;344.e2838.

18. Practice bulletin no. 145: antepartum foetal surveillance. Obstet Gynecol. 2014;124(1):182-92.

Cite this article as: Mukhopadhyay B, Ahmad SN, Agarwal S, Kabra S. Evaluation of feto-maternal outcome using AFI and SDVP for amniotic fluid assessment; Which is a better method?. Int $\mathbf{J}$ Reprod Contracept Obstet Gynecol 2017;6:3109-12. 